\title{
O periódico Seara no Timor Português (1949-1973): práticas de mediação e integração institucional pela imprensa católica
}

\author{
Alexandre Fernandes \\ Doutorando em Antropologia Social pela Universidade de Brasília \\ alexfernandes@unb.br
}

\begin{abstract}
Resumo Este artigo é um esforço de imaginação histórico-etnográfica voltado à compreensão da ação missionária católica promovida pela Diocese de Díli no Timor Português. Tal esforço foi estimulado pela leitura dos números do periódico Seara, publicado entre 1949 e 1973 pela Diocese de Díli. Inspirado nas análises de Clifford Geertz e Eric Wolf sobre o papel dos "mediadores" para a produção de conexões sociológicas entre escalas globais e locais, argumento que uma das principais ações da Diocese de Díli consistia em harmonizar as ações dos missionários em Timor com as diretivas vindas do Vaticano e do Estado Português, atuando como uma mediadora que transmitia (e subvertia) os projetos globais da Igreja Católica. A produção e distribuição de Seara era uma das práticas pelas quais a mediação se realizava. De uma perspectiva diacrônica sobre tais práticas, discuto transformações nos projetos da Santa Sé no Timor Português assim como nas versões que a própria Diocese de Díli dava a essas instruções.
\end{abstract}

Palavras-chave: mediação, missionários, Timor Português, Concílio Vaticano II.

\section{Introdução}

$\mathrm{D}$ esde a reestruturação de sua independência, Timor-Leste é reconhecido por ser um país cuja população é majoritariamente católica. (U.S. Department of State, 2007). Há relativo consenso na literatura antropológica e histórica (Boarccaech, 2013; Fidalgo, 2012) de que tal fato resultou do aumento vertiginoso da conversão ao cristianismo católico durante a ocupação indonésia (1975-1999) e que o início da implantação da Igreja Católica Apostólica Romana em Timor-Leste e da expansão de sua influência se deu no período da colonização portuguesa (1596-1975). No entanto, ainda que seja feita uma relação de causalidade entre a ação missionária no período colonial português e o grandioso número de católicos, há um relativo vácuo na produção historiográfica e antropológica sobre a atuação dos missionários no então Timor Português.

Ciente disso, esse artigo é produto de um esforço de imaginação etnográfica voltada à compreensão da ação missionária católica no Timor Português, especificamente no período entre o início da Diocese de Díli e o fim da colonização portuguesa (1940-1975). Tal esforço foi realizado pela leitura dos números de Seara, periódico escrito e publicado pela Diocese de Díli, órgão da Igreja Católica responsável pela administração da missão católica na colônia, editados de 1949 a 1973. Para certos 
estudos sobre catolicismo no Timor-Leste (Paulino, 2012), Seara é um dos principais testemunhos da ação missionária no Timor Português. Tal periódico tem sido tomado também como fonte de informação para a construção de uma imaginação do passado, apropriado de modo a justificar projetos e ansiedades políticas contemporâneas de ordem nacional (Silva, 2007)

$\mathrm{O}$ acesso a Seara se deu mediante pesquisa em arquivos realizada durante o período de 18 de setembro a 9 de dezembro de 2013 em Lisboa, Portugal. Além do periódico Seara, foi realizada a leitura de arquivos, livros e boletins que partem dos contextos semântico (missionários católicos no Timor Português) e temporal (primeiros três quartos do século $\mathrm{XX}$ ) nos quais a produção e a circulação de Seara se davam. Tanto Seara quanto outros textos foram encontrados nos seguintes arquivos e bibliotecas: $\mathrm{Bi}-$ blioteca Nacional de Portugal, Sociedade de Geografia de Lisboa, Arquivo Histórico Ultramarino e Arquivo Histórico Diplomático. No movimento de cunho etnográfico, que leve em conta, em certa medida, o ponto de vista nativo, propus-me a pensar Seara como uma modalidade de prática que expressa ansiedades políticas, além de atentar para as visões de mundo nela expressas (Bourdieu, 2007). Desse modo, o foco da análise é pensar Seara como um meio de comunicação persuasivo dos seus editores-escritores para o seu público-alvo.

Uma vez que se fazia necessário ter uma compreensão de dimensões (emissor(es), receptor(es), mensagens, referentes, códigos) em que tal prática de comunicação ocorria, buscou-se compreender seu contexto de produção, circulação e consumo. Em termos gerais, observou-se que Seara era produzida pela Diocese de Díli que, dentro da organização da Igreja Católica, tinha originalmente como finalidade realizar mediações entre as agências metropolitanas da instituição e os missionários e, como será demonstrado, os fiéis que se encontravam dispostos pelo território do Timor Português. Naquele contexto, Seara tornou-se um dos instrumentos de operacionalização dessa mediação. Tal caráter cosmopolita da Diocese de Díli, voltado tanto para o contexto global da Igreja Católica quanto para o contexto local dos missionários no Timor Português, se transpôs em Seara, que se mostrava como um periódico em que se conjugavam textos metropolitanos e da própria Diocese de Díli para divulgação aos membros da Igreja Católica que se encontravam em Timor.

O fenômeno comunicativo expresso em Seara possibilita refletir sobre dinâmicas de mediação entre diferentes escalas de interação, entre o local e global, uma vez que esse periódico era uma tecnologia mobilizada por certos mediadores para que integrações entre diferentes escalas de ação e governo se efetivassem. Sobre os mediadores, Eric Wolf (2003) e
Clifford Geertz (1960) foram antropólogos pioneiros em discuti-los como pauta antropológica, na medida em que destacaram a importância de determinados agentes na articulação de diferentes contextos sociais e ordens morais. Wolf, em sua análise sobre os funcionários enviados pela Coroa Espanhola ao México, sugere que eles foram sujeitos que permitiram o surgimento de alianças entre as comunidades locais no território mexicano e outras localizadas em contextos europeus. Já Geertz entende que os mediadores são importantes para compreender as transformações sociais pelas quais uma determinada população passa, uma vez que são esses atores que as conectam a contextos sociais mais amplos. Geertz, em seu estudo sobre os "kijajis", uma figura tradicional na Ilha de Java, sugere que eles foram agentes essenciais para a formação do estado nacional indonésio, pois foram "personas" que mediaram as relações entre comunidades camponesas da Ilha de Java com as elites da capital indonésia, Jacarta.

A questão que motivou os investimentos intelectuais referidos dizia respeito à compreensão do papel dos mediadores como construtores e subversores de ordens morais globais. Wolf (2003) sugere que, por serem atribuídos poderes políticos aos funcionários da coroa, esses mediadores acabaram por adquirir, paulatinamente, um papel essencial nas organizações locais, tornando-se detentores do poder político local e entrando em conflito com a Coroa Espanhola. Geertz, por sua vez, destaca como o fato de as elites javanesas terem utilizado desses professores islâmicos fez que eles se empoderassem a tal ponto que o estado indonésio começou a ser menos "secular" e mais "islâmico". Porém, ainda que entender as subversões de projetos maiores por grupos locais seja uma importante questão para estudo da mediação, os investimentos desses antropólogos não focalizaram como esses grupos e indivíduos realizavam tais práticas de subversão.

Neste texto, procuro refletir sobre a prática da mediação de uma perspectiva particular: tematizo os modos pelos quais uma tecnologia de mediação (a imprensa) produza a própria mediação. Nesses termos, a análise etnográfica de Seara permite contribuir para reflexão do modo como coletivos mundiais e locais se relacionam, uma vez que a produção e a difusão de Seara objetivavam colocar diferentes grupos em contato. Não menos importante, tal análise também permite contribuir para construir um conhecimento histórico sobre quais foram as ansiedades e questões missionárias da Diocese de Díli durante o período de colonização portuguesa, momento fundamental para a formação de uma maioria católica no Timor-Leste contemporâneo.

$\mathrm{O}$ artigo é dividido em três seções. Na primeira, busco situar o leitor no universo de ação social da 
Diocese de Díli e de Seara. Argumento que a Diocese de Díli, em sua origem, foi concebida com o papel de conectar as cúpulas da Igreja Católica e do Estado Português com os diferentes integrantes da Igreja que atuavam no Timor Português, harmonizando as ações das diferentes agências católicas operantes no território de modo a gerar maior coesão institucional. Seara estava à serviço desse projeto, traduzindo e comunicando ideias e valores passados pelas cúpulas da Igreja Católica para seus agentes lotados na colônia.

$\mathrm{Na}$ segunda seção, procuro compreender, em termos gerais, como eram transmitidas, em forma e conteúdo, as ideias e valores que permitiam a mediação por meio de Seara. Nesse sentido, sugiro que a Diocese de Díli apresentava os projetos transmitidos pelas agências metropolitanas por meio da divulgação de artigos que tratavam de inúmeras dimensões das missões religiosas. Da mesma maneira, demonstro que os textos de autoria da Diocese de Díli eram uma forma de instrumentalizar e reforçar projetos globais da Igreja para o contexto do Timor Português, produzindo e divulgando conhecimentos dos missionários em Timor sobre o território e as populações locais.

$\mathrm{Na}$ terceira seção, dando continuidade à compreensão das práticas de mediação, procuro, de modo mais atento, interpretar mudanças nas ansiedades políticas veiculadas em Seara a longo de seu período de existência. Tais ansiedades expressavam expectativas divergentes a respeito de como a reconfiguração sociocultural das práticas missionárias e das populações que eram delas objeto deveria se dar. Assim, sugiro que a Diocese de Díli buscou mediar novas formas de conceber como cristianizar o Timor Português diante das reformas pelas quais a Igreja Católica passou, cuja expressão máxima de reforma foi o Concílio Vaticano II (1961-1965). Como será demonstrado, esse evento implicou para o periódico Seara a diminuição do seu papel de mediar ansiedades nacionalistas do Estado Português e a redução dos investimentos na formação de clérigos timorenses. A partir de então, a Igreja passou a investir diretamente na formação do apostolado dos leigos e a ter uma maior tolerância aos movimentos comunistas e ao avanço do protestantismo. Tais fatos participaram do processo pelo qual a pauta de ação "civilizatória” da Igreja deu lugar a uma pauta "culturalista". Naquele contexto, os investimentos dos missionários não deveriam mais trabalhar para extinguir o particular, a cultura. Pelo contrário, sugeria-se que a cultura fosse utilizada como suporte para transmitir a mensagem cristã.

\section{Seara como técnica de mediação da Diocese de Díli}

Diferentemente de certas denominações protestantes, que se organizam mediante células relativamente independentes entre si (Beidelman, 1982), a Igreja Católica é uma instituição estruturada por órgãos hierarquizados, sendo a Santa Sé o órgão central e as Dioceses órgãos responsáveis por evangelizar as diferentes áreas do globo terrestre. Essa hierarquia coloca a Cúria Romana, comandada pelo Papa e por Cardeais, como o órgão central da Igreja, enquanto as dioceses, comandadas por bispos, são circunscrições eclesiásticas que atuam em nome do Papa nas diversas unidades sociopolíticas em que a Igreja atua. Nos territórios coloniais, os bispos atuavam como administradores eclesiásticos que comandavam unidades circunscricionais menores: as paróquias - para o pastoreio dos agentes coloniais e suas famílias que viviam nas áreas urbanas - e as missões religiosas, para as populações autóctones a ser convertidas.

Antes de 1940, a circunscrição eclesiástica do Timor Português era administrada pela Diocese de Macau, China. Entretanto, diante de reestruturações promovidas pelo novo regime político instalado na metrópole a partir de 1926, que acarretou a entrada de António Salazar na chefia de governo, surgiu o Acordo Missionário entre o Estado português e a Igreja Católica em 1940 (Cruz, 1997). Além de uma aproximação para fins do Império Português, tais como a entrega de recursos para a Igreja implantar escolas nas colônias, esse acordo criou uma nova Diocese no Timor Português, estabelecida na capital da colônia, Díli.

A Diocese de Díli, chefiada por um bispo, comandou a missão religiosa no Timor Português, uma vez que era um território majoritariamente composto por pagãos. Ela era composta por unidades menores - a Paróquia de Díli e as missões religiosas no interior da colônia. Desse modo, o governador da "missão de Timor" (no singular) era o Bispo da Diocese de Díli, sendo as "missões de Timor" (no plural) governadas cada uma por um padre missionário, que trabalhava em conjunto com irmãos e irmãs missionários. Assim, pode-se observar que a missão religiosa no Timor Português foi uma organização composta por diferentes pessoas e aparelhos. Sua ação foi coordenada, hierarquizada e estruturada por uma divisão social do trabalho.

Por ter surgido do fortalecimento da associação com o Estado português, a Diocese era compreendida pelo corpo de integrantes do Estado português e da Igreja Católica como um instrumento para harmonizar as missões católicas com os projetos coloniais do Estado português. Observa-se o papel da Diocese de 
Figura 1 - Mapa missionário do Timor Português (1965)

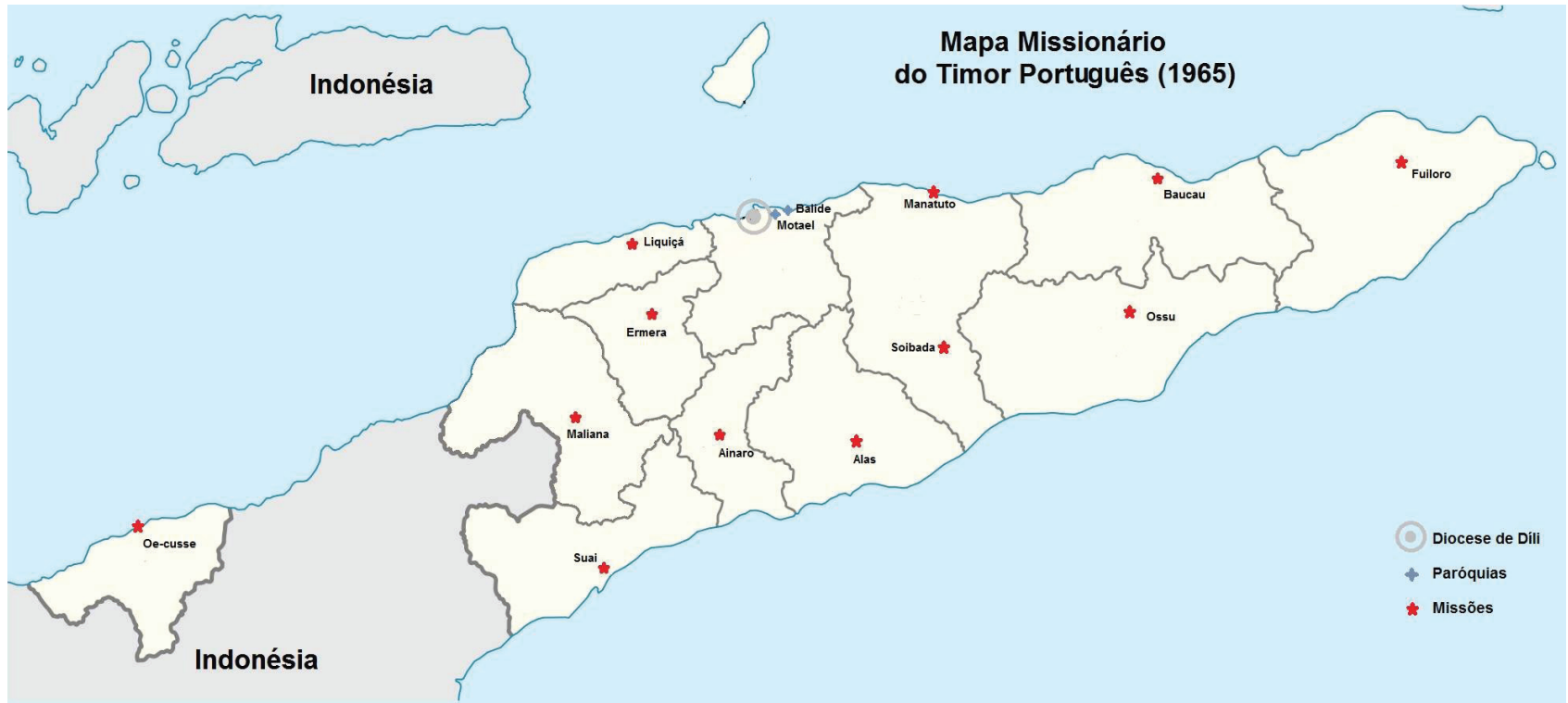

Díli como "mediadora", uma vez que conectava os missionários entre si, e eles a complexos institucionais como o Estado português e a Santa Sé. A Diocese de Díli promovia, portanto, várias sinapses, podendo ser tomada como uma mediadora fundamental. O seguinte esquema, simplificador por não considerar muitos outros agentes importantes, explica mais ou menos como se buscava manter a coordenação de ações dos missionários de Timor no que diz respeito à Igreja Católica e ao Estado português:

Figura 2 - Esquema de relações entre os diferentes coletivos na Europa (Metrópole) e no Timor Português (Colônia).

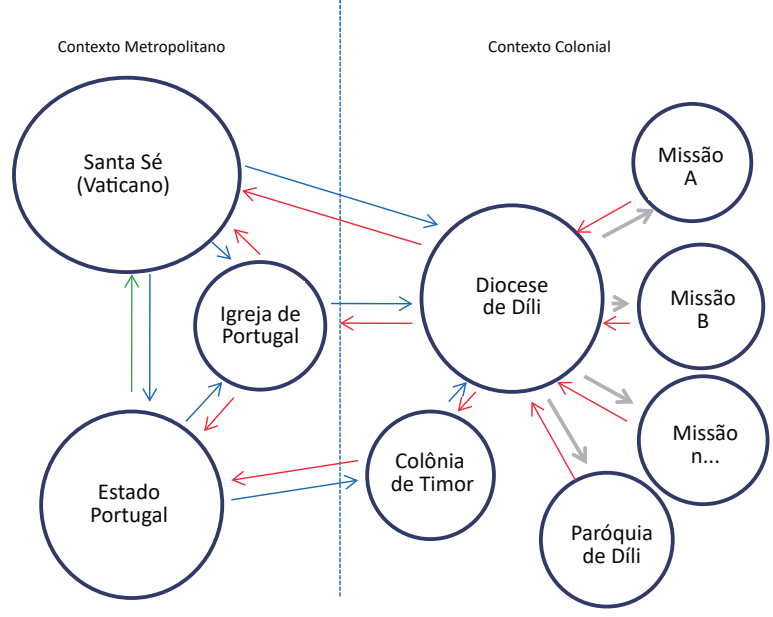

Nota: A Diocese de Díli estava a serviço de conectar esses diferentes atores. Seara era uma das mediações da Diocese pensada para os missionários integrantes da Paróquia de Díli e das missões religiosas no interior do Timor Português (setas verdes).

Assim, com base na oposição entre "solidariedade orgânica" e "solidariedade mecânica" (Durkheim, 2010), é possível observar que essas relações sociais buscavam estabelecer dois efeitos. O primeiro era for- mar uma comunidade de pessoas que se relacionam, entre as quais podemos citar o papa da Igreja Católica, o chefe de governo do Estado português, os arcebispos da Igreja Católica em Portugal, o governador do Timor Português, o Bispo da Diocese de Díli e, finalmente, os missionários lotados em Timor. O segundo efeito desejado era estabelecer uma coletividade que compartilhasse mais ou menos ideias e valores semelhantes, ou seja, modos de perceber e de se comunicar.

Com a observação de que a Diocese de Díli era o principal mediador da Igreja Católica e do Estado português com os missionários no Timor e destes entre si, percebe-se que Seara era uma tecnologia para produzir a atividade de mediação. Em termos globais, o periódico era editado pela Diocese de Díli, com textos feitos pelos órgãos centrais da Igreja Católica na metrópole e pela própria Diocese e cujos destinatários eram (inicialmente) os missionários no Timor Português. Trata-se, portanto, de uma das faces da mediação da Diocese de Díli, pois promovia a comunicação das agências centrais da Igreja e da própria Diocese com seus agentes de base em Díli e no interior da Colônia, fortalecendo a harmonização das ideias e valores dos missionários diante das agendas evangelizadoras e colonizadoras, respectivamente, da Igreja Católica e do Estado português.

Inicialmente com periodicidade mensal, o primeiro número de Seara foi lançado em janeiro de 1949, nove anos após a fundação da Diocese. Um dos escritos do Padre Ezequiel Pascoal, o primeiro editor de Seara, indicou que a imprensa era um dos principais instrumentos para a atuação da Diocese de Díli: "Creio que não há diocese alguma que não tenha o seu boletim. É um elemento necessário - orienta, coordena esforços, suscita energia, propõe alvitres, estimula iniciativas" (Seara, jan. 1949, p. 10). 
O pequeno trecho citado revela que Seara era visto por diferentes atores missionários como um instrumento de produção da coordenação da ação dos diferentes missionários que estavam sob a hierarquia da Diocese de Díli. Do mesmo modo, a imprensa era entendida pela Diocese como uma das formas de guiar a ação dos missionários vinculados a Diocese de Timor: "[Seara] É o eco da voz veneranda do Sumo Pontífice [o papa] e do prelado diocesano [o Bispo], pois, arquiva suas decisões, transmite os seus desejos, põe-nos, em suma, em contacto mais directo com todos aqueles que estão entregues aos seus desvelos pastorais" (Seara, jan. 1949, p. 10).

Desse modo, observando-se o contexto organizacional e a formação da Diocese de Díli, é possível entender que Seara foi uma tecnologia utilizada para que a Diocese realizasse uma de suas funções institucionais, que era atuar como mediadora diante da cúpula da Igreja em Roma e seus missionários no Timor Português, bem como diante de projetos e interesses de instituições do Estado português - metropolitanas ou não - e das lideranças da Diocese no Timor junto a agentes de base de ambas as instituições (Igreja e Estado) atuantes na Colônia. Com isso, sugere-se que, por meio desse periódico e de outras ações, a Diocese de Díli comunicou alguns dos projetos institucionais da Igreja Católica e do Estado português aos integrantes da Igreja e do Estado colonial lotados no Timor Português.

\section{A mediação pela reprodução de instruções globais e por conhecimentos sobre o contexto timorense}

A Diocese de Díli buscava ser obedecida, acreditada e reconhecida por diferentes missionários que atuavam em nome da Igreja no Timor Português. Para o alcance de tal eficácia, os discursos registrados no periódico se faziam por meio da mobilização de um conjunto de ideias e valores relativamente compartilhados, ainda que passíveis de conflito e contestação. Uma leitura panorâmica de inúmeros textos publicados em diferentes números de Seara torna possível identificar algumas características fundamentais do repertório de representações que permitia que a mediação ocorresse e a diocese fosse reconhecida e obedecida.

Primeiramente, destaca-se o fato de que a estrutura de Seara era uma metonímia da hierarquia eclesiástica. A diagramação do boletim era um espelho da posição dos autores dos textos aí publicados. Uma vez que "O Sumo Pontífice é (...) o primeiro missionário e superior de todas as missões, que governa quer diretamente, quer por intermédio da Propaganda ou pelos seus vigários" (Rego, 1961), seus textos tinham lugar de destaque na publicação, ocupando as primeiras páginas de Seara. Agentes com capital social diferenciado, desde o ponto de vista da hierarquia da Igreja, tinham suas contribuições à Seara dispostas em lugares que refletiam tal posição hierárquica. O boletim dava primazia aos textos escritos por superiores da Igreja; a seguir vinham os textos instrucionais da Diocese de Díli; por fim, publicavam-se reflexões locais de agentes como padres, irmãos e irmãs que atuavam no Timor Português.

Os índices dos números de Seara entre 19491964 expressavam a hierarquia na produção de conhecimentos para os missionários, em que os primeiros textos foram originalmente escritos pelo Vaticano, os textos intermediários foram produzidos pela Igreja Metropolitana de Portugal e os textos finais pela Diocese de Díli. Assim, tendo-se em conta os efeitos sociológicos da hierarquia na produção simbólica do conhecimento, a estrutura de poder da Igreja fez que, dentro do espaço de enunciação de Seara, a Santa Sé e a Igreja Metropolitana de Portugal tivessem maior expressão autoral nos textos do periódico. A Diocese, por ser a mediadora, ocupou uma posição intermediária na disposição dos textos de Seara; o seu esforço foi traduzir para aquele contexto diversas reflexões mais gerais. Os missionários lotados em Timor, por sua vez, pouco contribuíram na produção da ciência missionária. Desse modo, observa-se que Seara mobilizava textos de diferentes autores, que se dispunham entre si hierarquicamente.

A segunda característica importante para que a prática de mediação acontecesse era a amplitude de temas e gêneros textuais apresentada no periódico. Os textos em Seara abordavam todas as dimensões da vida de uma missão. Diferentes assuntos eram tratados no periódico, uma vez que os produtores dos textos tinham, no seu horizonte de reflexões, as múltiplas relações associadas à ação de expansão do cristianismo.

Nos textos com formatos de artigos, havia discussões sobre teologia, medicina, geografia, direito e comunicação social. Seara parecia ter uma preferência pela publicação de textos teológicos, que buscavam os fundamentos bíblicos e conciliais que justificavam a ação missionária e evangelizadora da Igreja Católica. Entretanto, havia também textos de ordem jurídica, em que se refletia sobre as relações jurídicas entre os vários corpos que orientavam a expansão missionária. Um terceiro gênero textual comum eram artigos que tratavam sobre a prática missionária: como captar vocações missionárias, como formar missionários, adentrar novos métodos de evangelização e de fixação da 
Igreja Católica em territórios ainda não convertidos, e meios de buscar a aproximação dos missionários às populações autóctones, adaptando aos contextos indígenas de acordo com as pedagogias, as línguas e as artes dessas populações não cristãs. Por fim, havia também um conjunto de textos que refletia sobre "a história das missões", que se ocupava em pensar o processo histórico de expansão do cristianismo. Entendendo que precisariam envolver as diferentes disciplinas científicas para pensar sobre a produção da "expansão do cristianismo", Seara poderia ser concebido como um periódico multidisciplinar.

Além desses textos mais formais, havia outros gêneros textuais, tais como lendas, contos, nomeações de missionários, referências às datas comemorativas do Estado português, intenções de orações cuja determinação vinha do Vaticano, relatos sobre experiências missionárias em outras regiões do Globo e notícias. Tendo em conta tais fatos, pode-se classificar Seara como um "fato social total” (Mauss, 2008), uma vez que não se tratou apenas de um instrumento político-religioso da Igreja. Seara era pensado, a um só tempo, como um periódico jurídico, científico, econômico, político e religioso. A mediação era feita por mensagens que abordavam fatos que iam muito além da gestão da organização interna da Igreja, de modo que englobavam várias dimensões da vida dos seus leitores e das instituições das quais participavam.

Por fim, a terceira característica que também permitia a prática de mediação era o caráter autoreflexivo e experimental de parte dos textos veiculados por Seara. Apesar de os membros da Igreja serem normalmente reconhecidos pela literatura antropológica por serem orientados por uma postura dogmática e teleológica para dar sentido às suas práticas (Simonian, 1999; Van der Geest, 1990), apareciam em Seara reflexões marcadas por incertezas, dúvidas, por uma positividade de reflexão sobre experimentos para a construção de novas formas de realizar a atuação missionária. Não por acaso, Seara era pensado pelos seus editores como um meio de divulgar missiologia, conhecimento referente às missões que "amadurece" com a prática cotidiana dos missionários, por tentativas e métodos: "a missiologia não é mais do que a codificação das conclusões tiradas de métodos, de tentativas, de experiências, durante séculos, e em todas as latitudes, por milhares de missionários" (Pascoal, mar.-abr. 1950).

A positivação da "inovação" era, por sua vez, o que legitimava a autoria de textos pela Diocese de Díli e os missionários a ela vinculados. Para que as intenções e vontades dos órgãos centrais da Igreja Católica se efetivassem, fazia-se necessário conhecer melhor os não cristãos do Timor Português. Nesse sentido, os missionários de Timor investiam na publicação da produção de material folclórico, etnográ- fico e antropológico. Com relação à etnografia dos missionários, por exemplo, para conseguir fazer que houvesse uma "penetração reveladora" do Cristianismo, Padre Ezequiel Pascoal afirmou a necessidade dos missionários em conhecer "os gentios", tanto pela "mentalidade" quanto pela "orgânica social": "É indispensável escalpelizar os males causados pelo paganismo e patenteá-los, em toda a sua extensão, para que todos os homens (...) sintam a necessidade e a urgência que há em concorrer para o triunfo da obra missionária" (Pascoal, maio-jun. 1954).

Observa-se que, naquele contexto, houve uma preocupação por compreender as populações com fundamento em categorias pensadas como sendo a base da unidade humana: "religião", "orgânica social", "deficiências e taras", "riquezas morais". Essas foram categorias de uma gramática para constituição de pontos de contato entre o que os missionários entendiam como cristianismo e paganismo. Tal empreendimento foi semelhante em inúmeros outros contextos sociais, tais como os observados na ação missionária católica em Angola durante o início do século XX (Dulley, 2010) e entre os Bororo, em Mato Grosso do Sul (Montero, 2012).

Assim, podem-se tecer, provisoriamente, algumas características de como a mediação pelo periódico Seara se efetivava. O destaque dado aos textos das cúpulas da Igreja decorria da hierarquia, uma vez que as cúpulas tinham interpretações mais legítimas sobre como a Igreja Católica deveria expandir o cristianismo. A segunda característica consistia no fato de a mediação ser realizada a partir da mobilização de fatos relacionados a diversos domínios de ação social, de que são exemplares questões como: Por que missionar? Como agir com os pagãos e os novos cristãos? Como organizar as missões e suas relações internas e externas? Qual é a história das missões religiosas? Por fim, a positivação da experiência prática pode ser identificada como a terceira característica das mediações realizadas por Seara. Por meio da veiculação de textos que tratavam da práxis da missionação, Seara, a um só tempo, valorizava e reconhecia as práticas de seus agentes de base e construía um repertório de respostas às grandes e diversas questões que mobilizavam reflexão. Essa necessidade de aprimorar as ações das missões para a expansão da Igreja Católica era o que justificava uma prática de divulgação de textos de autoria dos missionários no Timor Português, prática pela qual eles e suas experiências eram enredados, englobados e integrados na ação global da Igreja.

Assim, é possível pensar que a divulgação de textos formais, de notícias e textos literários - produzidos tanto no contexto metropolitano como pelos próprios missionários - foi uma das formas pelas quais a Diocese fez que os missionários aprendessem, aperfeiçoassem e obedecessem às instruções de como pro- 
mover a ação missionária em Timor ao mesmo tempo em que suas práticas eram reconhecidas e integradas como ação da Igreja.

\section{As ansiedades políticas mediadas pela Diocese de Díli por meio de Seara (1949-1973)}

Identificamos acima alguns dos modos pelos quais Seara exercia a mediação entre diferentes dimensões da ação global da Igreja Católica e de agentes oficiosamente a serviço dela - agentes estatais, entre outros. Nesta seção, busco discutir transformações das atividades de mediação da Diocese de Díli em quatro períodos distintos: 1) o período entre 1949 e 1954, momento que corresponde ao início de sua edição até a sua paralisação durante o ano de 1955; 2) o período entre 1956 e 1960, quando o periódico voltou a ser editado, até o início do Concílio Vaticano II; 3) o período de 1961 a 1964, momento em que as discussões conciliares foram acompanhadas no próprio periódico, levando à sua interrupção durante o ano de 1965; e 4) o período de 1966 a 1973, momento em que houve uma reinauguração do periódico com um formato de jornal, em vista das novas normativas da Igreja Católica decorridas do Concílio.

\section{Uma missão católico-portuguesa pela salvação e nacionalização do Timor (1949-1955)}

Conforme foi afirmado no primeiro tópico, a Diocese de Díli surgiu num contexto de acordo da Igreja Católica com o Estado português, que significou uma reestruturação aproximativa da relação entre essas duas instituições. Tal fato fez que, no início da divulgação de Seara, a mensagem de promoção nacional e de conexão entre "evangelização" e "lusitanização" tivesse um grande destaque, havendo uma afirmação constante de que "evangelizar é nacionalizar". Num artigo teológico, encontram-se as seguintes palavras motivadoras: “(...) a consciência missionária não é apenas um dever; é também um dever nacional (...) a consciência missionária é um dever nacional, exigido pelo presente. (...) Os missionários não são, é certo, os únicos civilizadores, mas são os melhores" (Consciência..., set. 1949, p. 237).

Em conjunto com essa pauta nacionalista, o momento histórico era também de combate a duas frentes tidas como ameaças à Igreja Católica: o comunis- mo e as igrejas protestantes, chamadas criticamente de "seitas". Enquanto a Igreja Católica enfrentava no Leste-Europeu um avanço de estados que retiravam dela alguns privilégios (A Hungria..., jan.-fev. 1957), no contexto ocidental a Igreja enfrentava o avanço constante de igrejas protestantes (Pascoal, jul. 1949). A qualificação de tais fatos como ameaças ao catolicismo, contudo, não era de modo contínuo pelos textos de autoria local da Diocese de Díli no periódico. Isso porque as Igrejas protestantes não tinham grande inserção no território do Timor Português, tampouco havia coletivos estruturados em defesa de ideias e projetos considerados comunistas.

Destaca-se também o lugar de proeminência dado às discussões sobre práticas para a formação de clérigos indígenas. Seara transmitia mensagens da Santa Sé que promovia a formação do clero indígena, uma preocupação em constituir, nesses novos integrantes da Igreja, a sua santidade.

\footnotetext{
Das nações católicas e dos países de missões eleva-se o mesmo brado: Mais sacerdotes! Mais missionários! Peçamos para que apareçam em Timor verdadeiras e desinteressadas vocações entre timorenses para que eles próprios levem ao seio dos seus irmãos o facho da luz evangélica que missionários de Portugal vieram aqui acender e tem mantido aceso durante quatro séculos. (Apostolado..., mar. 1949, p. 68).
}

Do mesmo modo, havia uma transmissão da ansiedade fundamental da Santa Sé na evangelização dos povos não cristãos mediante a transformação das alianças matrimoniais das populações missionadas. Os textos de autoria da Santa Sé traziam noções de que a poligamia e o divórcio, entre outras, eram práticas a ser combatidas. A Diocese de Díli buscou dar sentido ao combate à poligamia no Timor Português. Em decorrência disso, o editor do periódico, Padre Ezequiel Pascoal, apresentou os diferentes problemas que a poligamia causava na população do Timor Português, tais como a "corrupção permanente" e um "ambiente não consentâneo para a criação dos filhos": "a poligamia entre os timorenses pagãos tem de atribuir-se à moleza enervante do clima que provoca uma espécie de hiperestesia sensual livre de qualquer freio" (Poligamia, maio-jun., 1954).

A Diocese de Díli, em textos de sua autoria, reverberava também tais discussões identificando o barlaque - uma instituição social local caracterizada pelos missionários como "um contrato mediante o qual um homem adquire uma mulher para o seu convívio marital em troca de um número, previamente estipulado com a família desta, de búfalos, de cavalos, de espadas ou de uma determinada quantia de dinheiro" (Poligamia, maio-jun., 1954) - como um problema para a evangelização do Timor Português. 
Somavam-se às discussões sobre casamento o tratamento dos "cultos" indígenas. As etnografias desses fenômenos eram extremamente recorrentes na produção de textos de autoria da própria Diocese de Díli, caracterizando, com base na categoria "religião", os timorenses como "animistas" (Pascoal, set.-out. 1954). A observação da categoria local chamada lúlic foi entendida como um "culto aos objetos" (O culto..., jan. 1949, p. 13), prática que era tratada como algo que contrariava uma etiqueta própria ao cristianismo, na perspectiva dos padres missionários daquele contexto. Do mesmo modo, havia um exercício constante de registrar as "lendas", procurando compreender, por exemplo, as versões locais de uma questão tida como universal: como os timorenses entendem a "origem do mundo". Uma vez descoberta tal versão, caberia aos missionários combater a lenda para tornar os timorenses cristãos, de modo a ter uma percepção sobre a questão da origem do mundo de acordo com o livro bíblico Gênesis (Pascoal, jan.-fev. 1950).

Com isso, é possível considerar que, durante esse período, a Igreja Católica na Europa e a Diocese de Díli promoviam a "civilização" como o projeto colonizador, em que procurava extinguir práticas que fossem entendidas como contrárias ao cristianismo. Do mesmo modo, em face de um momento de grande proximidade com o Estado português, havia uma ênfase na nacionalização dessa população. Quanto às práticas locais, o barlaque, o culto aos lúlics e as lendas fantasiosas, cabiam aos missionários extingui-las, fazendo que os nativos se casassem aos moldes do "casamento europeu", cultuassem apenas o Deus cristão e compreendessem seu universo de acordo com os ensinamentos bíblicos.

\section{O início da dissociação com as práticas coloniais do Império português (1956-1960)}

As reformulações geopolíticas mundiais decorrentes do fim da Segunda Guerra Mundial produziram diversos efeitos na Igreja Católica, uma vez que os impérios coloniais europeus começaram a perder a hegemonia para novos estados emergentes, como Estados Unidos e União Soviética. Nesse contexto, as ações de instituições coloniais no Timor Português também passaram a ser colocadas em xeque, produzindo novas ansiedades e negociações nos anos que se seguiram. A Diocese de Díli, tal como se manifesta no boletim Seara, reagiu a este novo contexto. Em resposta aos movimentos anticolonialistas, Seara reacomodou discursos e ações das instituições que ela representava e mediava.
Os movimentos anticolonialistas começavam a ser tidos como ameaças a Igreja Católica, uma vez que os missionários eram vistos como associados aos colonizadores dos impérios. Por tal razão, uma das tendências em Seara foi afirmar que a missão religiosa do Timor Português estava dissociada da pauta nacionalista do Estado português, ainda que houvesse certa proliferação, nesse momento, de ideais luso-tropicalistas que promoviam o crescimento do Estado português (Barros, ago.-dez. 1956, p. 100). A noção de "cultura", por sua vez, emergia em Seara como uma categoria de reflexão importante sobre como "cristianizar". "Civilizar" começava a ter um poder de persuasão diminuído.

Outro ponto a se destacar refere-se à proposta, organizada pelo Vaticano, de reorganização da hierarquia eclesiástica, de modo a expandir aqueles que eram considerados parte da Igreja. A partir de então, começou, cada vez mais, a se proliferar ideais favoráveis aos catecúmenos (leigos) como figuras essenciais para a cristianização (A estrutura..., jan.-jul. 1956, p. 12). O investimento na formação e prática do laicato passou a ser, assim, objeto de investimento da Diocese de Díli a fim de fomentar a missionação no Timor Português (Apostolado..., jan.-fev. 1958). No ano de 1958, relatos sobre congressos internacionais da Igreja Católica começavam a tratar o "apostolado do leigo" como uma questão.

A Diocese de Díli também começou a chamar a atenção para novas formas de atuação dos padres missionários. A ideia de formar paróquias, comunidades de pessoas centradas na figura da Igreja, foi reforçada, seguindo a recomendação do Papa Pio XII (Uma recomendação..., maio-jun. 1958, p. 120). Desse modo, a paróquia comunitária pareceu emergir como uma forma mais importante de transformar as sociedades (Nova..., jan.-fev. 1957).

A partir de 1961, por motivos desconhecidos pela pesquisa, Seara passou a ter uma periodicidade irregular. Além disso, a produção local ficou mais restrita e a ênfase nos quatro anos consecutivos, durante o período conciliar, foi a apresentação de textos produzidos pelas cúpulas.

\section{Seara durante o Concílio Vaticano II (1961-1964)}

Durante os anos conciliares (25 de dezembro de 1961 a 8 de dezembro de 1965), em conjunto com diferentes agentes da Santa Sé, realizaram-se diversas transformações nos modos da Igreja Católica se apresentar e atuar. Em relação às formas de apostolar, houve transformações em como as missas deveriam ser reali- 
zadas. Por meio de Seara, a Diocese de Díli informou as alterações que aconteceram durante o Concílio.

A atmosfera de renovação durante o Concílio teve certa reflexão na distribuição de poderes missionários. De algum modo, é perceptível que a Santa Sé começou a dar maiores competências aos Bispos. Observa-se que os textos metropolitanos divulgados em Seara mostraram aos missionários no Timor Português um movimento da Igreja Católica em repensar a sua ortodoxia (O novo..., nov.-dez. 1960, p. 203). Uma maior abertura do cristianismo católico às contingências e visões de mundo locais começou a ser discutida, na medida em que foi se dando maior abertura às dioceses para controlarem as formas de apostolado.

Nesse sentido, o caráter elástico da ortodoxia nos ambientes de missão, se antes era visto como um "mal necessário", passou a ser positivado como desejável e adequado. Em vez do combate ao paganismo, a adaptação do cristianismo ao "particular" começou a ser uma característica recebida cada vez mais com menor resistência. Isso fica expresso, por exemplo, em sugestões metropolitanas para as missões religiosas católicas de Portugal não mais impor o batizado aos moldes ortodoxos. Em um texto, um padre interroga se a identificação dos rituais locais visava a sua supressão ou sua potenciação para fins de missionação:

As adaptações da Liturgia, agora em estudo para as Missões deveriam aproveitar mais o ritual e desdobrar, por exemplo, aqueles repetidos no exercício do Baptismo, não para os suprimir nem simplificar, claro, mas para ver substituídas por eles as cerimónias gentílicas de iniciação da juventude. (A nova..., nov.-dez. 1960).

Isso fez que novas formas de lidar com a diferença fossem se constituindo. Não por acaso, em Seara, emergiram novas formas de dar sentido às trocas matrimoniais realizadas pelas populações que habitavam o Timor Português. Se, no período de vigência do regime jurídico do Indigenato, o casamento gentílico não tinha eficácia para produzir efeitos civis, os quais só eram reconhecidos pelo casamento canônico, a partir do Decreto $n^{\circ} 43.897$, de 6 de setembro de 1961, o chamado casamento gentílico passou a produzir tais efeitos, independente do sacramento católico: "Os casamentos gentílicos referentes ao período iniciado pelo Decreto (...) gozam de plena eficácia jurídica, nos termos deste diploma especial, embora sejam casamentos de indivíduos em regime de cidadania" (Validade..., jan.-abr. 1964, p. 31).

Tais transformações nas formas de como lidar com as populações nas missões e nas colônias foram transmitidas aos missionários em Timor Português pela Diocese de Díli, de modo a mudar as perspectivas sobre como compreender outras ideias e valo- res. Assim, na pequena produção missiológica local, começou-se a não tentar mais se extinguir práticas "gentis" e "pagãs", mas em ver até que ponto essas práticas poderiam ser utilizadas para o fim da cristianização (Deus..., maio-jun. 1960). Desse modo, vê-se que o período conciliar foi um momento em que a Diocese de Díli trouxe grandes inovações missiológicas, uma vez que se permitiu a criatividade nas formas de apostolar. Ao buscar pela maior eficácia da cristianização, a ortodoxia da Igreja esteve em um processo de descentralização.

\section{De Boletim para revista semanal: Seara na missão pela cultura e para/pelos leigos (1966-1973)}

Terminadas as reuniões conciliares, durante o primeiro ano após o fim do Concílio, Seara informou aos seus leitores as amplas discussões sobre os efeitos da reunião suprema da Igreja. Nesse sentido, uma grande quantidade de textos produzidos na metrópole foi republicada em Seara, de modo a apresentar quais foram as reformas impostas pelo Concílio Vaticano II. Num texto republicado pela Seara, resumiram-se quais seriam as reformas pelas quais a Igreja Católica tinha passado (Principais..., 27 jul. 1966). Em referência à autoconcepção da Igreja Católica, o padre autor informou que esta não "se vê a si própria como um absoluto. É toda de Deus e toda para os homens". A forma como a Igreja deveria lidar com as outras confissões cristãs protestantes foi reformulada. Sobre essas, o Padre Yes Congar afirmou que o ecumenismo da Igreja, agora, tem o "reconhecimento de um certo carácter de Igreja às outras confissões cristãs". Do mesmo modo, a Igreja rompeu com a "universalidade da religião cristã" - "Sobre as religiões não-cristãs, a Igreja não pretende para si o monopólio da religião", afirmou o padre.

Os efeitos do Concílio ficaram expressos em Seara, não apenas pelos textos que eram presentes, mas pelo próprio formato. Em janeiro de 1966, a Diocese de Díli, ao retomar o periódico, passou a publicar Seara em tamanho de jornal e com uma periodicidade semanal. Houve um aumento do tamanho das folhas, mas também uma redução do número de páginas. Mais importante, no entanto, foi que Seara mudou o seu público-alvo. Os leigos passaram a ser entendidos como potenciais leitores do periódico, na medida em que ela não era mais um periódico apenas para os missionários.

Sobre essa transformação, na primeira edição no novo formato, o editor de Seara lançou uma nota em que afirmou que, ao assumir as reformas propostas 
pelo Concílio Vaticano II, Seara abria-se para se comunicar com a população leiga: "Seara surge desta vez na esteira do Concílio Vaticano II" (Seara, 18 jan. 1966). Assim, a Diocese reformulou as funções institucionais do periódico Seara. Se antes a Diocese buscava a articulação das missões religiosas no Timor Português às agências metropolitanas por meio do periódico, trazendo os projetos destas e as traduzindo por meio da produção missiológica local, Seara passou a ser uma técnica que comunicava os projetos das agências metropolitanas diretamente às populações leigas no Timor Português. Seções do jornal Seara como "O Evangelho do Domingo... na vida da Semana" (3 maio 1966) tentaram mostrar como as lições do Evangelho, ensinadas nas missas do domingo, deveriam ser atualizadas no cotidiano dos fiéis.

Em cumprimento às instruções vindas do Concílio, a Diocese de Díli começou a chamar, cada vez mais, os leigos para a Igreja Católica. Se, em certo sentido, a ênfase anterior foi procurar por sacerdotes indígenas, a concepção de que os leigos são apóstolos da Igreja se tornou extremamente importante (Assim..., 3 maio 1996).

Outra reforma produzida pelo Concílio Vaticano II foi uma nova forma de como lidar com os fenômenos do protestantismo. Se antes eram categorias para nomear coletividades consideradas concorrentes e inimigas, o Concílio Vaticano II impôs novas diretivas sobre como a Igreja deveria se relacionar com esses fenômenos. Nesse sentido, em Seara, foram reproduzidos alguns pronunciamentos que pregavam o "respeito às igrejas protestantes" (Reflexões..., 16 fev. 1968). No entanto, ainda que a Igreja Católica tenha se proposto a cultivar maior tolerância aos fenômenos e instituições derivadas da reforma protestante, há diversos textos que mostravam permanências e continuidades de uma concepção que apresentava o catolicismo como o verdadeiro cristianismo (Será..., 1970). Assim, pode-se mostrar que o Concílio Vaticano II, ainda que tenha trazido a ideia de "ecumenismo", a busca pela fraternidade da Igreja foi transmitida pela Diocese de Díli de maneira dúbia, uma vez que o ecumenismo, movimento que prega uma maior tolerância e respeito às diferentes igrejas, era um ponto controvertido.

Com relação ao comunismo, a Diocese de Díli informou, por meio de Seara, que a Igreja Católica "evitaria sentenças de condenação ao comunismo" (Visão..., 10 ago. 1966). Assim, as encíclicas em que o Papa Pio XII condenava o comunismo foram revogadas e o Comunismo passou a ser visto, ambiguamente, como uma questão tolerada. Por vezes, os textos publicados em Seara também continuaram a relatar os problemas que o comunismo provocara para o funcionamento da Igreja. Uma pequena nota mostrou que a Igreja sofreu problemas na Tche- coslováquia, Polônia e Hungria, como a redução e expulsão de padres, mas também relatando fatos esperançosos de que, apesar dos conflitos, "a Cruz de Cristo do Cardeal Wyszynski é - pelo menos espiritualmente - mais forte do que a foice e o martelo do «Premier» Gomulka..." (A situação..., 3 ago. 1966).

Ainda que movimentos críticos à aliança da Igreja com o Estado português já viessem se anunciando há pelo menos uma década, a Diocese de Díli manteve-se contínua na defesa do Império português, contrapondo-se às afirmações de racismo e exploração a ele atribuídas. Sobre isso, a Diocese de Díli divulgou alguns textos em que afirmava que Portugal jamais fora racista em suas formas de colonizar e que tal acusação era produto de interesses "subversivos" de alguns países. Do mesmo modo, houve a manutenção de textos que acompanhavam "a doença de Salazar", o chefe de governo de Portugal (Portugal..., 22 abr. 1967.). Com isso, é interessante observar que, ainda que o Concílio Vaticano II tenha efetivado um distanciamento da Igreja das práticas de governos estatais, essa busca pela purificação do cristianismo fica pouco expressa em Seara. Entretanto, comparativamente, houve uma redução das reflexões sobre os diplomas legais de Portugal e os seus projetos para o Ultramar. Tais dados nos permitem aventar que, como impacto do Concílio Vaticano II, a Diocese de Díli passou a assumir um papel de mediadora entre, prioritariamente, as instruções vindas da Santa Sé e da Igreja Católica portuguesa e a comunidade católica em Timor.

A maior possibilidade de criar novas formas de apostolar para as Dioceses e a busca por uma nova forma de pensar a ortodoxia fizeram que o Concílio Vaticano II incluísse, dentro de um movimento global próprio dos anos 1960, o discurso de "respeito à cultura". Nas reflexões sobre o Concílio, um texto metropolitano informou que a Igreja Católica teria de se tornar mais "local". (Visão..., 10 ago. 1966) Assim, uma das instruções da Diocese de Díli, incorporando os discursos teológicos advindos do Concílio, foi o que se chamou de "tentativas de adaptação à cultura". Nesse sentido, a Igreja teria de agir levando em conta certas especificidades locais: "É o justamento respeitoso, prudente, cientificamente e teològicamente válido da Igreja a uma cultura particular, em face da atitude, do comportamento exterior e da aproximação apostólica prática" (A Igreja..., 7 jun. 1969).

A Igreja Católica, assim, começava um esforço pela "culturalização" de suas atividades pastorais. A primeira foi a exigência de traduções de diversos textos litúrgicos, orações e bíblias para línguas locais. Desse modo, é interessante observar que Seara começou a se tornar um periódico bilíngue, não apenas divulgando artigos em português, mas também nas 
línguas nativas do Timor Português. Um exemplo disso é a divulgação de traduções das narrativas bíblicas para língua tétum (Tentativa..., 7 ago. 1971). A Diocese de Díli, num esforço de "culturalizar" a "religião cristã", começou a realizar esforços de tradução linguística de maneira inédita. Ainda que os missionários católicos tenham feito, historicamente, traduções de livros de catequese, os atos litúrgicos da Igreja, como as missas, sempre tinham sido realizados em latim. A Igreja, nesse sentido, foi quem começou a tentar falar na própria língua dos timorenses.

Além da língua, a Diocese de Díli começou a se utilizar de reflexões sobre os timorenses, advindas das etnografias missionárias, para pensar como, através da cultura e dos usos e costumes, a religião católica poderia ser proliferada. As tentativas de conhecer os usos e costumes não tinham mais como objetivo a sua supressão posterior, mas a sua potencialização como instrumento de comunicação entre dois mundos. Na leitura de Seara, é possível observar que a produção missiológica local buscou dar sentido à instrução das cúpulas para que fizessem que a religião católica se "adaptasse à cultura local". Três atos litúrgicos da Igreja receberam especial relevo: casamento, batismo e catequese.

Com relação à catequese, numa instrução pastoral (Correio..., 30 ago. 1969), o novo Bispo José Joaquim Ribeiro afirmou que, em Timor, os padres e irmãos deveriam catequizar aos moldes timorenses, falando na língua local os ensinamentos bíblicos. A respeito do batismo, um missionário no Timor Português, o Padre Quintão, buscou fazer traduções da celebração para Tétum (Quintão, 18 set. 1971). Neste sentido, ele procurou palavras que corresponderiam às palavras em português (ou latim), assim como também instruía os missionários a como pronunciá-las. Interessante também foram as mudanças nas formas como o casamento gentílico passou a ser concebido. Nas suas observações, Padre Quintão afirmou que o "barlaque" e o "fetosá-umané" envolviam uma série de "trocas comerciais", uma vez que homens pagavam "cauções da noiva" para o pai, assim como havia a permuta de bens (búfalos, bélac etc). Apesar disso, Padre Quintão argumentou que a mulher tem o consentimento, sendo equivocada a percepção dos missionários de que as mulheres não tinham escolha:

O barlaque timorense, nas suas múltiplas versões ideológico-sinonímicas, refere-se a uma compra da noiva. (...) Mas, se a mulher, dalgum modo ou em pleno sentido, é vendida, e porque ela aceita, não forçada mas livremente, essa venda, diferenciando, desta sorte, a sua venda da venda de qualquer ser inanimado ou irracional o dum servo. (Quintão, 25 dez. 1971).
Nesse sentido, Padre Quintão argumentou pela "tolerância à cultura timorense" afirmando que, ainda que haja permutas de bens, o "casamento nativo" tem de ser incorporado pela Igreja.

\section{Considerações finais}

A observação etnográfica de Seara permite sugerir que, para a produção da mediação, os órgãos centrais da Igreja Católica nas metrópoles tinham de realizar uma infinidade de atividades, como promover conferências, escrever e enviar textos por navios e aviões para as dioceses etc. A Diocese de Díli, por sua vez, tinha de receber essas instruções, selecioná-las, editá-las, produzir reflexões sobre essas instruções e encaminhá-las aos diferentes missionários que atuavam nas estações missionárias. Isso se fazia não apenas pela transmissão de textos vindos das metrópoles, mas pela produção textual local, baseada nas experiências dos missionários nas gestões das relações com o espaço físico e com as populações do Timor Português. Assim, é possível pensar que a reprodução de textos como etnografias e folclores missionários foi uma das formas pelas quais a Diocese fez que os missionários aprendessem, aperfeiçoassem e obedecessem às instruções de como promover a ação missionária em Timor e, com isso, integrasse as ações locais e globais da Igreja e de seus missionários. Era por meio de um conjunto de reflexões hierarquizadas de determinadas questões, persuasivas, entre outras razões, por se basearem em dogmas e experiências, que a Diocese de Díli mediava projetos.

A perspectiva diacrônica da análise dos textos Seara permite reconhecer a missão religiosa católica no devirhistórico, mostrando que houve alterações substantivas na sua forma de atuar no Timor Português (e em outros contextos). Se o ideal cristianizador que fundamentou a criação da Diocese de Díli era de uma ordem semântica da "civilização" e "nacionalização", esse órgão começou a instruir os missionários subordinados a pensar o cristianismo como "espiritualidade" e "moralidade", por meio de discussões e resoluções pautadas pelo Concílio Vaticano II. Essas mudanças significaram uma reestruturação de todas as instruções que eram passadas pela Diocese de Díli, que podem ser expressas por diversas tendências: o ecumenismo (maior reconhecimento e tolerância às Igrejas Protestantes), um menor combate às práticas tidas "comunistas", um distanciamento da pauta compartilhada com o Estado Colonial português, uma menor rigorosidade com relação à ortodoxia, um menor foco na formação de clérigos para focalizar nos leigos e, principalmente, a eleição da cultura como um instrumento para cristianização e não mais de extinção. 


\section{Referências}

A ESTRUTURA da sociedade vai-se modificando. Seara, Díli, ano 8, n. 1, jan.-jul. 1956.

A HUNGRIA mártir (Da mensagem do Santo Padre Pio XII ao mundo, a 10/XI/1956). Seara, Díli, ano 9, n. 1, jan.-fev. 1957.

A IGREJA e as culturas. Seara, Díli, n. 148, 7 jun. 1969.

A NOVA reforma litúrgica. Seara, Díli, ano 12, n. 6, nov.dez. 1960.

APOSTOLADO da oração: intenções para o mês de abril. Seara, Díli, ano 1, n. 3, mar. 1949.

APOSTOLADO da oração: intenção geral para abril de 1958. Seara, Díli, ano 10, n. 1, jan.-fev. 1958.

A SITUAÇÃO da Igreja. Seara, Díli, ano 1, n. 29, 3 ago. 1966.

ASSIM deves estar na Igreja... Seara, Díli, ano 1, 3 maio 1996.

BARROS, Jorge de. O futuro do cristianismo no bloco Afro-Asiático. Seara, Díli, ano 8, n. 2, ago.-dez. 1956.

BEIDELMAN, T. O. Colonialism Evangelism: a sociohistorical study of an east african mission at the grassroots. Bloomington: Indiana University Press, 1982.

BOARCCAECH, A. A diferença entre iguais. São Paulo: Porto de Ideias, 2013.

BOURDIEU, P. Sistemas de ensino e sistemas de pensamento. In: A economia das trocas simbólicas. São Paulo: Perspectiva, 2007.

CONSCIÊNCIA missionária. Seara, Díli, ano 1, n. 9, set. 1949.

CORREIO do interior. Seara, Díli, ano 4, n. 154, 30 ago. 1969.

CRUZ, M. As negociações da Concordata e do Acordo Missionário de 1940. Análise Social, v. 32, n. 143/144, p. 815-845, 1997.

DEUS em Timor. Seara, Díli, ano 12, n. 3, maio-jun. 1960.

DULLEY, I. Deus é feiticeiro: prática e disputa nas missões católicas em Angola Colonial. São Paulo: Anna Blume, 2010.

DUR KHEIM, E. As regras do método sociológico. São Paulo: Martin Claret, 2010 [1895].

FERNANDES, A. Em searas do Timor Português: um estudo sobre as práticas de mediação da Diocese de Díli no período colonial (1949-1973). 2014. Dissertação (Mestrado em Antropologia Social) - Universidade de Brasília: Brasília, 2014.

FIDALGO, A. A religião em Timor Leste a partir de uma perspectiva histórico-antropológica. In: FIDALGO, A; BOUZA, E. Léxico fataluco-português. Díli, Timor Leste: Gráfica Pátria, 2012.

GEERTZ, C. The Javanese Kijaji: the changing role of a cultural broker. Comparative studies in Society and History, v. 2, n. 2, p. 228-249, 1960.

MAHMOOD, M. Citizen and subject: contemporary Africa and the legacy of late colonialism. Princeton: Princeton
University Press, 1996.

MAUSS, M. Ensaio sobre a dádiva. In: MAUSS, M. Sociologia e Antropologia. São Paulo: Cosac Naify, 2008.

MONTERO, P. Selvagens, civilizados, autênticos: a produção das diferenças nas etnografias salesianas (1920-1970). São Paulo: Edusp, 2012.

NOVA forma de apostolado: a formação de comunidades. Seara, Díli, ano 9, n. 1, jan.-fev. 1957.

O CULTO dos «Lulic». Seara, Díli, ano 1, n. 1, jan. 1949. O DESPORTO \& as Missões. Seara, Díli, ano 7, n. 6, nov.-dez. 1955.

O EVANGELHO do Domingo... na vida da Semana. Seara, Díli, 3 maio 1966.

O NOVO código das rubricas e dos breviários. Seara, Díli, Ano 12, n. 6, nov.-dez. 1960.

PASCOAL, E. O primeiro habitante de Timor. Seara, ano 2, n. 1-2, jan.-fev. 1950.

PASCOAL, E. Página missiológica: a poligamia. Seara, Díli, ano 6, n. 3, maio-jun. 1954.

PASCOAL, E. Página missiológica: alguns dos principais obstáculos à acção missionária em Timor, desde o seu início”. Seara, Díli, ano 6, n. 5, set.-out. 1954.

PASCOAL, E. Página missiológica. Seara, Díli, ano 2, n. 3-4, mar. abr. 1950

PASCOAL, E. Reacção. Seara, ano 1, n. 6, jul. 1949.

PAULINO, V. A imprensa católica Seara e a tradição timorense. In: SILVA, K.; SOUSA, L. Ita Maun Alin...: o livro do irmão mais novo. Colibri: Lisboa, 2012.

POLIGAMIA. Seara, Díli, ano 6, n. 3, maio-jun. 1954.

PORTUGAL tem razão. Seara, Díli, ano 2, 22 abr. 1967.

PRINCIPAIS aquisições teológicas do Concílio - segundo o Padre Yves Congar. Seara, Díli, 27 jul. 1966.

QUINTÃO, Padre. Celebração do baptismo em Tétum. Seara, Díli, ano 6, n. 207, 18 set. 1971.

QUINTÃO, Padre. Tentativas de adaptações: o casamento nativo”. Seara, Díli, ano 6, 25 dez. 1971.

REFLEXÕES sobre temas conciliares: 6) ecumenismo. Seara, Díli, n. 109, 16 fev. 1968.

REGO, A. da S. Lições de missionologia. Lisboa: Junta de Investigações do Ultramar, 1961. p. 55.

SEARA, Díli, ano 1, n. 1, jan. 1949.

SEARA, Díli, ano I, n. 1, 18 jan. 1966. [Nova Série].

SERÁ o protestantismo a verdadeira Igreja de Cristo? Seara, Díli, ano 5, n. 164, 1970.

SILVA, K. A Bíblia como constituição ou a constituição como Bíblia? Projetos para a construção do Estado-Nação em Timor-Leste. Horizontes Antropológicos, Porto Alegre, v. 13, n. 27, 2007.

SIMONIAN, L. A missão numa perspectiva antropológica. Novos Cadernos NAEA, v. 2, n. 1, p. 129-148, 1999.

TENTATIVA de adaptações: rito de matrimónio traduzido do Português para Tétum. B - Oração Universal e Bênção Nupcial. Seara, Díli, ano 6, n. 204, 7 ago. 1971.

UMA RECOMENDAÇÃO de Sua Santidade Pio XII. 
Seara, Díli, ano 10, n. 3, maio-jun. 1958.

U.S. DEPARTMENT OF STATE. Bureau of Democracy, Human Rights, and Labour. Timor-Leste: internacional religious freedom report. 2007. Disponível em: <http:// www.state.gov/j/drl/rls/irf/2007/90135.htm>. Acesso em: 6 jan. 2014.

VALIDADE dos casamentos consuetudinários chinês e Timor". Seara, Díli, ano 2 (nova série), jan.-abr. 1964.

VAN DER GEEST, S. Anthropologists and missionaries: brothers under the Skin. Man, v. 25, n. 4, p. 588-601, 1990. VISÃO geral do Concílio: os grandes problemas do nosso tempo foram debatidos com a maior seriedade no «Vaticano

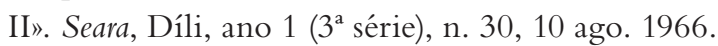

WOLF, E. Aspectos das relações de grupo em uma sociedade complexa: México. In: BIANCO, B.; RIBEIRO, G. Antropologia e poder: contribuições de Eric Wolf. Brasília: UnB, 2003.

\title{
Seara journal in Portuguese Timor (1949-1973): mediation practices and institutional integration by the Catholic press
}

\begin{abstract}
This article is a historical and ethnographic imagination effort to understand some dimensions of the Catholic missionary action promoted by the Diocese of Dili in Portuguese Timor. Such effort was stimulated by the reading of Seara, a journal published between 1949 and 1973. Inspired by the analysis of Clifford Geertz and Eric Wolf about the role of "mediators" for the production of sociological connections between global and local scales, I argue that one of the main actions of the Diocese of Dili was to harmonize the actions of missionaries in Timor with the directives of the Vatican and the Portuguese State, acting as a mediator that transmitted (and subverted) the global projects of the Catholic Church. The production and distribution of Seara by the Diocese of Dili was one of the practices by which mediation was performed. From a diachronic perspective, I discuss the changes in the projects of the Vatican in Timor and those versions that Diocese of Díli gave to these instructions.
\end{abstract}

Keywords: Mediation, Missionaries, Portuguese Timor, Second Vatican Council.

\section{La revista Seara en el Timor portugués (1949-1973): prácticas de mediación y la integración institucional por parte de la prensa católica}

\section{Resumen}

Este artículo es un esfuerzo de imaginación histórica y etnográfica dirigido a la comprensión de la acción misionera católica promovida por la Diócesis de Dili en el Timor Portugués. Este esfuerzo se vio estimulado por la lectura de los números del periódico Seara publicados entre 1949 y 1973 por la Diócesis de Dili. Inspirado en el análisis de Clifford Geertz y de Eric Wolf sobre el papel de los "mediadores" para la producción de conexiones sociológicas entre las escalas global y local, sostengo que una de las principales acciones del la Diócesis de Dili fue armonizar los esfuerzos de los misioneros en Timor con las directrices procedentes del Vaticano y del Estado portugués. La Diócesis de Dili sirvió como un mediador que transmite (y subvierte) los proyectos mundiales de la Iglesia Católica. La producción y la distribución de Seara era una de las prácticas por las cuales se realizaba la mediación. Desde una perspectiva diacrónica de este tipo de prácticas, discuto los cambios en los proyectos del Vaticano en el Timor portugués, así como en las versiones que la Diócesis de Dili daba a esas instrucciones.

Palabras clave: Mediación, Misioneros, Timor Portugués, Vaticano II.

Data de recebimento do artigo: 23/08/2016

Data de aprovação do artigo: 15/12/2016 
